\title{
Assessing the Role of Particles in Radiative Heat Transfer during Oxy-Combustion of Coal and Biomass Blends
}

\author{
Gautham Krishnamoorthy and Caitlyn Wolf \\ Department of Chemical Engineering, University of North Dakota, 241 Centennial Drive, Stop 7101, Grand Forks, ND 58201, USA \\ Correspondence should be addressed to Gautham Krishnamoorthy; gautham.krishnamoorthy@engr.und.edu
}

Received 30 November 2014; Accepted 29 January 2015

Academic Editor: Constantine D. Rakopoulos

Copyright (c) 2015 G. Krishnamoorthy and C. Wolf. This is an open access article distributed under the Creative Commons Attribution License, which permits unrestricted use, distribution, and reproduction in any medium, provided the original work is properly cited.

\begin{abstract}
This study assesses the required fidelities in modeling particle radiative properties and particle size distributions (PSDs) of combusting particles in Computational Fluid Dynamics (CFD) investigations of radiative heat transfer during oxy-combustion of coal and biomass blends. Simulations of air and oxy-combustion of coal/biomass blends in a $0.5 \mathrm{MW}$ combustion test facility were carried out and compared against recent measurements of incident radiative fluxes. The prediction variations to the combusting particle radiative properties, particle swelling during devolatilization, scattering phase function, biomass devolatilization models, and the resolution (diameter intervals) employed in the fuel PSD were assessed. While the wall incident radiative flux predictions compared reasonably well with the experimental measurements, accounting for the variations in the fuel, char and ash radiative properties were deemed to be important as they strongly influenced the incident radiative fluxes and the temperature predictions in these strongly radiating flames. In addition, particle swelling and the diameter intervals also influenced the incident radiative fluxes primarily by impacting the particle extinction coefficients. This study highlights the necessity for careful selection of particle radiative property, and diameter interval parameters and the need for fuel fragmentation models to adequately predict the fly ash PSD in CFD simulations of coal/biomass combustion.
\end{abstract}

\section{Introduction}

Radiative transfer from the dispersed phase particulates is important during the combustion of pulverized fuels [1]. The parent fuel, char, fly ash, and soot participate in the radiative transfer process with their radiative properties determined by their size, shape, and composition [2]. The radiative properties of these particulates (absorption and scattering efficiencies, scattering phase functions) are a function of wavelength of light and are often estimated from codes based on the Mie theory [3] or experimental measurements [4, 5]. However, in order to keep the radiation compute time within reasonable limits in combustion simulations, constant absorption and scattering efficiencies or spectrally averaged Planck mean absorption coefficients for the particulates have been proposed. These Planck-averaged properties are dependent on temperature as well as the assumed size distribution of the particles. Furthermore, results from employing these spectrally averaged particle properties have been mixed, with some investigators confirming their adequacy [6], whereas others have attributed large errors to their usage along with their dependence on the particle size distribution (PSD) $[3,7]$ which in turn has significant challenges associated with its predictability in pulverized-fuel boilers.

The role of particle radiation has received increased attention in recent years as technologies for carbon capture such as oxy-combustion with flue gas recycle to regulate the temperature are being actively investigated for scale-up and commercialization $[8,9]$. The thermal and chemical effects associated with an increased $\mathrm{CO}_{2}$ concentration within the furnace can impact fuel devolatilization and burnout, temperature, radiative heat transfer profiles, and the evolution of the size-segregated fly ash PSD within the boiler. In addition, the volumetric flow rate of the flue gas circulating through the furnace is generally reduced during oxy-combustion and there is the possibility of uncaptured fly ash being recirculated and accumulating within the boiler. While significant efforts have been expended towards developing high fidelity models 
for the gas radiation properties in these scenarios due to high concentrations of radiatively participating gases [10-13], the role of particle radiation has largely been overlooked and has been modeled by employing either constant absorption and scattering coefficients throughout the domain [14] or constant absorption and scattering efficiencies of the combusting particle [15].

However, it is well known that a combusting particle undergoes significant changes to its absorption and scattering characteristics in a combusting environment as it transitions from a parent fuel to char to an ash particle $[1,2]$. Furthermore, the final PSD of the ash particles following char combustion and burnout cannot be explained solely by a shrinking sphere methodology that has been implemented in most CFD codes. For instance, there is a considerable body of literature that discusses fuel fragmentation during devolatilization/char burnout that eventually determines the final PSD of the ash particles [16, 17]. Therefore, the overall goal of this paper is to assess the need for high fidelity particle radiative property and aerosol models that can capture the PSD of fly ash particles under these newer operating conditions. By taking advantage of recent radiative transfer measurements made in a $0.5 \mathrm{MW}$ combustion test facility during combustion of coal-biomass blends under air-fired and oxyfired conditions [18], a sensitivity study is performed that examines the incident radiative flux variations to the radiative properties of the combusting particle, particle swelling during devolatilization, and the resolution of the fuel PSD at the inlet. In addition, prediction sensitivities to the particle scattering phase function and biomass devolatilization models were also examined.

\section{Methods}

2.1. Experimental Data. The simulations reported in this paper are based on a series of experimental measurements of incident radiative heat fluxes during oxy-combustion of coal and biomass blends carried out in a $0.5 \mathrm{MW}$ Combustion Test Facility at RWE npower [18]. The interested reader is referred to the original publication for the experimental details which are only briefly described here. The furnace is approximately $4 \mathrm{~m}$ long with an inner cross-section of $0.8 \mathrm{~m} \times$ $0.8 \mathrm{~m}$. The primary air velocity was maintained at $15 \mathrm{~m} / \mathrm{s}$ in all of the experiments with the secondary air velocity adjusted to obtain an exit $\mathrm{O}_{2}$ composition of $3 \%$. The fuels PSD along with their proximate and ultimate analysis were also provided in the original reference [18]. Wall incident radiative flux measurements at different locations along the furnace during combustion in air and a once through, dry recycle of flue gas were reported at different recycle ratios (RR) with an experimental uncertainty of $\pm 4 \%$. The $R R$ was defined as

$$
\mathrm{RR}=\frac{\mathrm{mRFG}}{\mathrm{mRFG}+\mathrm{mPFG}} .
$$

mRFG and mPFG correspond to the masses of the recycled flue gas and the product gases, respectively. The simulations in this study correspond to the experimental conditions of oxy-combustion with 75\% RR (hereby designated as "oxy$75 \%$ RR") and combustion under air-fired conditions. For all the simulations, the $\mathrm{O}_{2}$ concentration in the primary stream was maintained at $21 \%$ (by volume). In the $75 \%$ RR scenario, the $\mathrm{O}_{2}$ concentration in the secondary stream was $28 \%$ (by volume).

2.2. CFD Modeling. The CFD modeling was carried out using the commercial code ANSYS FLUENT (version 15) [19]. The $3 \mathrm{D}$ furnace was represented by $2 \mathrm{D}$ axisymmetric geometry consisting of 17, 296 cells to enable quick assessments of the different parameters investigated in this sensitivity study. This approach is similar to the $2 \mathrm{D}$ axisymmetric representation of this furnace previously carried out by $\mathrm{Hu}$ and $\mathrm{Yan}$ [14] and is justifiable by the fact that, for the radiative transfer assessments carried out in this study, it is important to adequately capture the temperature distribution within the combustor and maintain an identical volume to surface area ratio (or mean beam length) as the experimental conditions. The highly swirling flames investigated in this study would require millions of computational cells to adequately resolve all the gradients near the burner in a $3 \mathrm{D}$ representation thereby making the parametric assessments in this study very compute-intensive [15]. It was deemed critical to numerically capture the internal recirculation zone that was present in the experimental conditions for flame stabilization. This was undertaken in this study by employing the $2 \mathrm{D}$ axisymmetric solver with swirl in ANSYS FLUENT [19]. A very fine mesh was employed near the burner along with second order upwind discretization schemes for the momentum and turbulence variable transport equations to ensure that the results reported in this study were grid independent. The inlet PSD of the two coals (Russian and South African (SA)) and two types of biomass particles (Shea meal and saw dust) investigated in this study were fit to a two-parameter Rosin-Rammler distribution function characterized by a most probable particle size and a spread parameter. Figure 1 shows the fuel PSD against Rosin-Rammler curve fits for the different coal and biomass particles employed in this study. The vertical axis in Figure 1 denotes the mass fraction $\left(Y_{d}\right)$ of fuel particles that have a diameter that is greater than " $d$." The biomass particles are in general larger than the coal particles at the inlet.

The variables of interest in most radiative transfer analysis are the distributions of radiative heat flux vectors $(\mathbf{q}(\mathbf{r}))$ and the radiative source terms $(-\nabla \cdot \mathbf{q}(\mathbf{r}))$. Distributions of the radiative heat flux vectors are necessary to perform accurate energy balances on any solid/liquid interfaces within the solution domain and at the boundaries. The radiative source term describes the conservation of radiative energy within a control volume and goes into the energy balance equation associated with the fluid flow. Therefore, these variables couple radiation with the other physical processes that occur in a combustion simulation. In order to determine the distributions of these quantities, a transport equation describing the radiative transfer first needs to be solved.

If " $I$ " represents the directional intensity, $k$ the absorption coefficient (which is due to the gases as well as the particulates in the combustion media), $\sigma$ the scattering coefficient (due to the particulates alone), $I_{b}$ the black body emissive power, 


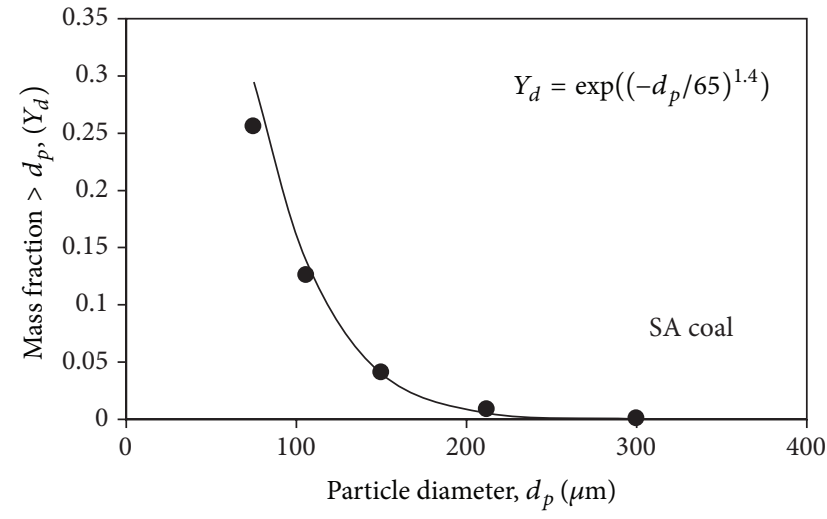

(a)

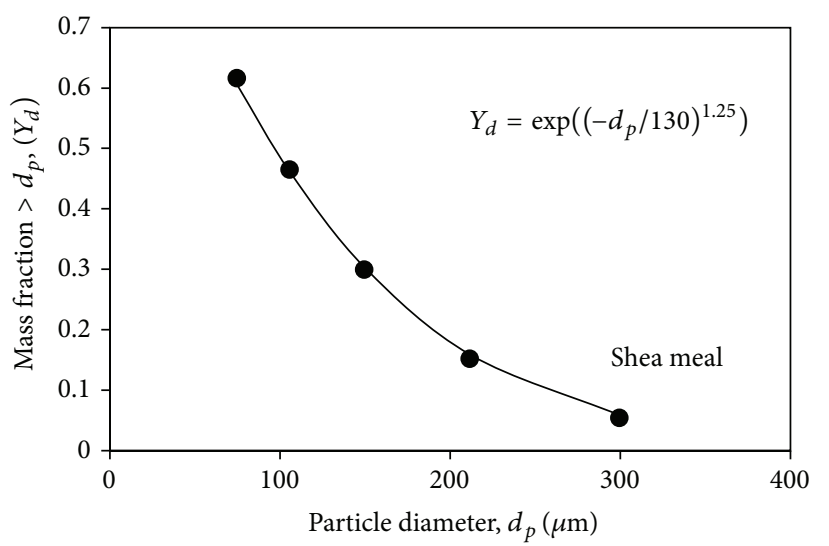

- Particle size distribution Rosin-Rammler curve fit

(c)

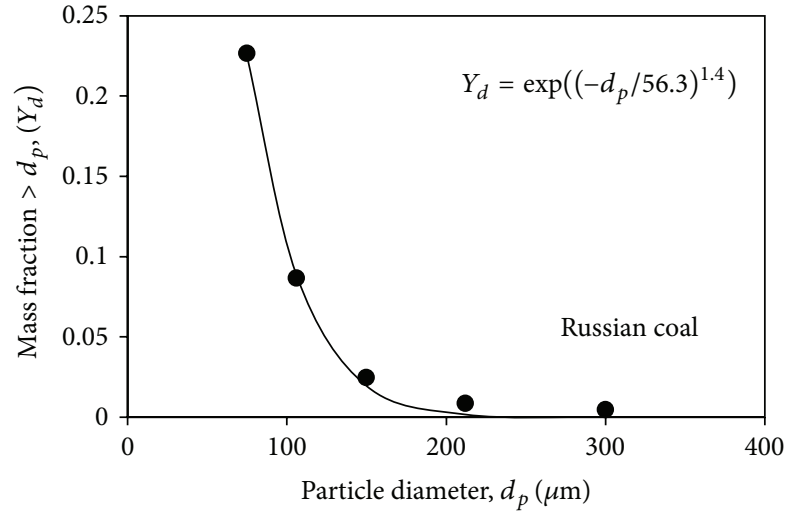

(b)

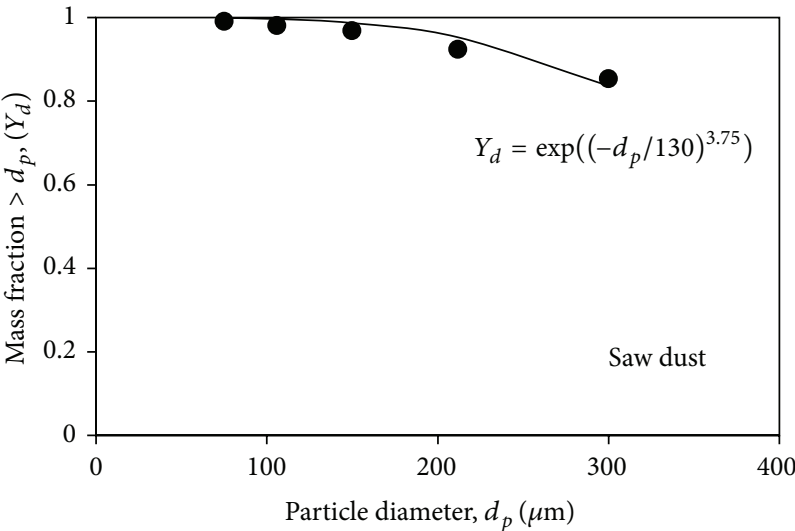

- Particle size distribution Rosin-Rammler curve fit

(d)

FIGURE 1: Fuel particle size distributions and Rosin-Rammler curve fits (a) SA coal; (b) Russian coal; (c) Shea meal; (d) saw dust.

and $\Phi$ the scattering phase function (assumed to be forward scattering for the bubbles), then the differential equation governing the radiative transfer can be written as

$$
\begin{aligned}
\nabla \cdot\left(I_{i}(\vec{r}, \widehat{s}) \widehat{s}\right)= & -\left(k_{g, i}+k_{p}+\sigma_{p}\right) I_{i}(\vec{r}, \widehat{s}) \\
& +k_{g, i} w_{g, i} I_{b g}(\vec{r}, \widehat{s})+k_{p} w_{p} I_{b p}(\vec{r}, \widehat{s}) \\
& +\frac{\sigma_{p}}{4 \pi} \int_{0}^{4 \pi} I_{i}(\vec{r}, \widehat{s}) \Phi\left(\widehat{s}, \hat{s}^{\prime}\right) d \Omega^{\prime} .
\end{aligned}
$$

In (2), the subscripts " $g$ " and " $p$ " correspond to the gasphase and particulate phase, respectively. The subscript " $i$ " corresponds to the "gray gas" employed to estimate the gas radiative properties and " $w$ " corresponds to the weighting factor associated with the blackbody emissive power. The gas radiative property modeling methodology adopted in this study falls under the category of weighted-sum-of-gray-gases (WSGG) models where the emissivities of gas mixtures are expressed in a functional form consisting of temperature independent absorption coefficients $\left(k_{i}\right)$ and temperature dependent weighting fractions $w_{i}(T)$. The WSGG model parameters employed in this study have been validated previously through comparisons against benchmark/line-by-line (LBL) data for prototypical problems that are representative of compositions, $\mathrm{H}_{2} \mathrm{O} / \mathrm{CO}_{2}$ ratios, and temperatures encountered during combustion in air and oxy-combustion $[11,20]$. For further details on the WSGG modeling methodology and the gas radiative property models employed in this study, the reader is referred to $[2,11]$. In this study, the particle radiative properties were assumed to be "gray," that is, maintained constant across all gray gases $(i)$, and the particle temperature was assumed to be equal to the surrounding gas temperature (i.e., $I_{b g}$ and $I_{b p}$ were equal at all spatial locations) [21].

The radiative heat fluxes within the domain or at a surface and the radiative flux divergence are determined by integrating over the solid angles $(\Omega)$ surrounding a point as [2]

$$
\begin{aligned}
\mathbf{q}(\mathbf{r}) & =\sum_{i} \int_{4 \pi} I(\mathbf{r}, \widehat{\mathbf{s}}) \widehat{\mathbf{s}} \mathrm{\Omega} \Omega \\
\nabla \cdot \mathbf{q}(\mathbf{r}) & =\sum_{i}\left(k_{g, i}(\mathbf{r})+k_{p, i}(\mathbf{r})\right)\left(4 \pi I_{b}(\mathbf{r})-G_{i}(\mathbf{r})\right) .
\end{aligned}
$$


$G$, the incident radiation, is calculated as

$$
G(\mathbf{r})=\sum_{i} \int_{4 \pi} I(\mathbf{r}, \widehat{\mathbf{s}}) \mathrm{d} \boldsymbol{\Omega} .
$$

The particle absorption and scattering coefficients of the particles in (2) were computed as

$$
\begin{aligned}
k_{p} & =\underset{V \rightarrow 0}{\operatorname{Limit}} \sum_{N} \varepsilon_{\mathrm{pn}} \frac{A_{\mathrm{pn}}}{V}=\underset{V \rightarrow 0}{\operatorname{Limit}_{V}} \sum_{N} Q_{\mathrm{abs}} \frac{A_{\mathrm{pn}}}{V} \\
\sigma_{p} & =\underset{V \rightarrow 0}{\operatorname{Limit}} \sum_{N}\left(1-\varepsilon_{\mathrm{pn}}\right)\left(1-f_{\mathrm{pn}}\right) \frac{A_{\mathrm{pn}}}{V} \\
& =\underset{V \rightarrow 0}{\operatorname{Limit}} \sum_{N} Q_{\mathrm{scat}} \frac{A_{\mathrm{pn}}}{V} .
\end{aligned}
$$

In (6) and (7), the summation is over $N$ particles within the control volume $V, \varepsilon_{\mathrm{pn}}$ is the particle emissivity, $A_{\mathrm{pn}}$ is the projected area of the $n$th particle, and $f_{\mathrm{pn}}$ is the scattering factor associated with the $n$th particle. $Q_{\text {abs }}$ and $Q_{\text {scat }}$ correspond to the absorption and scattering efficiencies, respectively. In this study, $Q_{\mathrm{abs}}$ and $Q_{\text {scat }}$ were assumed to vary as the combusting particle transitions from the parent fuel to char to an ash particle. This variation adopted in this study is shown in Table 1 . The variation in the coal radiative properties is according to Kuehlert [22]. These values indicate that the effective "extinction efficiency factors" are in the range 1.75 to 2.43 which compares well with the effective extinction factors reported by Mengüç et al. [5] for different sized particles. The absorption and scattering efficiencies of the biomass particles were based on the assumption that the absorption efficiency of biomass particles at the temperatures encountered in this study was roughly $50 \%$ of those of the coal particles and the scattering efficiencies were about $10 \%$ of those of coal particles [3]. In order to avail computational savings, the radiation calculations were performed once every 20 fluid/energy iterations. This approach has no bearing on the final results reported in this study and is justifiable by the fact that the radiation field does not change as rapidly between iterations as the fluid/temperature field. Furthermore, since the results reported in this study correspond to steady state calculations, the convergence in the radiation calculations was assessed at the end by ensuring radiative energy balance throughout the furnace. This was done by confirming that the volume integral of the radiative source term was equal to the surface integral of the net radiative flux through all the domain boundaries.

Other important physical model settings employed in the simulations are given in Table 2 and the interested reader is referred to the ANSYS FLUENT user's guide for further details on these models [19]. The primary modeling options were employed in all of the simulations explored in this study, unless otherwise indicated. The variable properties for the particles and the gas radiative property models were implemented in this study as user-defined functions (UDFs) in ANSYS FLUENT. The heterogeneous coal char combustion was modeled employing the intrinsic model which assumes that the surface reaction rate includes the effects of both
TABLE 1: Coal and biomass radiative property variations employed in the simulations.

(a)

\begin{tabular}{lccc}
\hline Coal & $\begin{array}{c}\text { Absorption } \\
\text { efficiency }\end{array}$ & $\begin{array}{c}\text { Scattering } \\
\text { efficiency }\end{array}$ & $\begin{array}{c}\text { Scattering/absorption } \\
\text { efficiency }\end{array}$ \\
\hline Parent fuel & 1.13 & 1.3 & 1.15 \\
Char & 0.59 & 1.5 & 2.54 \\
Ash & 0.05 & 1.7 & 34.00 \\
\hline
\end{tabular}

(b)

\begin{tabular}{lccc}
\hline Biomass & $\begin{array}{c}\text { Absorption } \\
\text { efficiency }\end{array}$ & $\begin{array}{c}\text { Scattering } \\
\text { efficiency }\end{array}$ & $\begin{array}{c}\text { Scattering/absorption } \\
\text { efficiency }\end{array}$ \\
\hline Parent fuel & 0.565 & 0.13 & 0.23 \\
Char & 0.295 & 0.15 & 0.51 \\
Ash & 0.025 & 0.17 & 6.80 \\
\hline
\end{tabular}
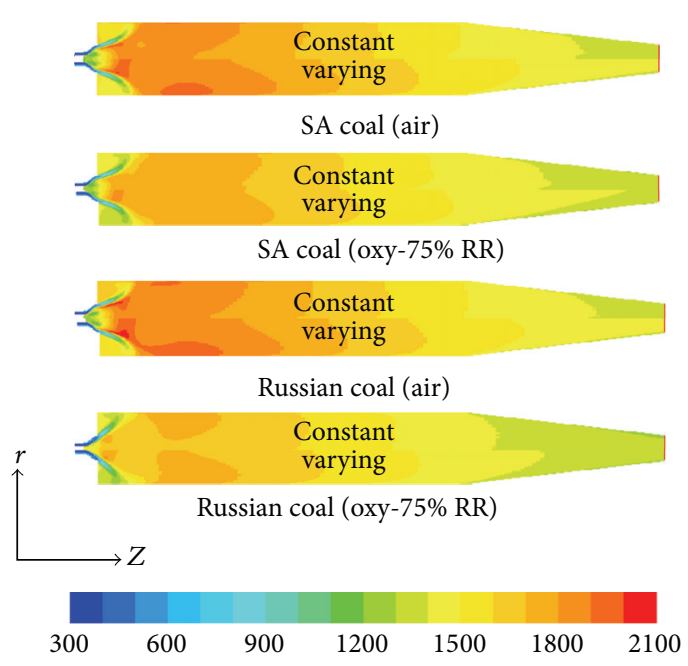

FIGURE 2: Temperature contours during the combustion of Russian and SA coal in air and in the oxy-75\% RR scenario (on the top half of the axisymmetric furnaces are the predictions from constant particle radiative properties; in bottom half are predictions from varying particle radiative properties).

bulk diffusion and surface reaction while the combustion of the biomass was assumed to be diffusion limited [19]. The thermal boundary conditions at the wall were set at emissivity of 0.6 with heat transfer coefficient of $14 \mathrm{~W} / \mathrm{m}^{2}-\mathrm{K}$ and surrounding fluid temperature of $300 \mathrm{~K}$ since the furnace was water jacketed [14].

\section{Results and Discussion}

3.1. Sensitivity to Particle Radiative Property during Coal Combustion. Figure 2 shows contours of temperature during the combustion of Russian and SA coal in air and in the oxy-75\% RR scenario. Two simulations were performed corresponding to each experimental condition: one in which the radiative properties of the combusting particles varied according to Table 1 and the second where the radiative 
TABLE 2: Summary of physical models employed in the CFD simulations.

\begin{tabular}{|c|c|c|}
\hline Physical models & Primary modeling option & $\begin{array}{l}\text { Other modeling options explored in the } \\
\text { sensitivity analysis }\end{array}$ \\
\hline Coal devolatilization & The two competing rates (Kobayashi) model & \\
\hline Biomass devolatilization & The two competing rates (Kobayashi) model & Constant devolatilization rate $\left(20 \mathrm{sec}^{-1}\right)$ \\
\hline Gas-phase chemistry & $\begin{array}{l}\text { Two steps: (1) char oxidation to } \mathrm{CO},(2) \mathrm{CO} \\
\text { oxidation to } \mathrm{CO}_{2}\end{array}$ & \\
\hline Gas-phase radiative property & Perry $(5 \mathrm{gg})[11]^{*}$ & \\
\hline Turbulence & Realizable $k-\varepsilon$ & \\
\hline Radiative transport equation solver & $\begin{array}{l}\text { Discrete ordinates method (angular } \\
\text { resolution, theta } \times \text { phi: } 3 \times 3 \text { ) }\end{array}$ & \\
\hline Particle radiative property & Variable $K_{\text {abs }}$ and $K_{\text {scat }}(\text { Table } 1)^{*}$ & $\begin{array}{l}\text { Constant } K_{\text {abs }} \text { and } K_{\text {scat }} \text { (corresponding to } \\
\text { that of char in cf. Table } 2 \text { ); }\end{array}$ \\
\hline Particle scattering phase function & Anisotropic (forward scattering) & Isotropic scattering \\
\hline Fuel particle size distribution (PSD) at inlet & $\begin{array}{l}\text { Rosin-Rammler distributions (Figure } 1 \text { ) } \\
\text { (8 diameter intervals) }\end{array}$ & $\begin{array}{l}\text { Rosin-Rammler distributions (Figure } 1 \text { ) } \\
\text { (40 diameter intervals) }\end{array}$ \\
\hline $\begin{array}{l}\text { Particle swelling coefficient } \\
\text { (during devolatilization) }\end{array}$ & $\begin{array}{l}1 \text { (no change in particle diameter } \\
\text { during devolatilization) }\end{array}$ & $\begin{array}{l}1.5 \text { (particle diameter increases by } 50 \% \\
\text { during devolatilization) }\end{array}$ \\
\hline
\end{tabular}

* These models were implemented as User-Defined Functions (UDFs) in ANSYS FLUENT.

properties were held constant (corresponding to that of the coal char in Table 1). These are labeled as "Varying" and "Constant" in the figure legends, respectively. While the temperature contours for the two coals are identical under similar firing conditions, oxy-firing at 75\% RR results in reduced temperatures resulting from the higher heat capacities of $\mathrm{CO}_{2}$. Furthermore, there are noticeable differences between the temperature fields predicted by the constant and varying particle properties.

Figure 3 shows contours of $\mathrm{CO}_{2}$ and $\mathrm{H}_{2} \mathrm{O}$ mole fractions during the combustion of Russian and SA coal in air and in the oxy-75\% RR scenario when employing varying particle radiative properties. The gas compositions are noticeably homogeneous downstream of the flame indicating the completion of devolatilization and combustion. In the simulations explored in this study, the $\mathrm{H}_{2} \mathrm{O} / \mathrm{CO}_{2}$ ratios at the furnace exit were in the range $0.35-0.65$ during combustion in air and in the range $0.08-0.10$ during oxy- $75 \% \mathrm{RR}$.

Figure 4 shows the contours of particle scattering coefficient to particle absorption coefficients $\left(\sigma_{p} / k_{p}\right)$. Since the scattering and absorption coefficients are directly proportional to the scattering and absorption efficiencies, respectively ((6) and (7)), this ratio (Table 1 ) is an indicator of the state of the combusting particles inside the furnace which increases from 1.15 for the parent coal particle to 34 when only ash is present within the furnace. For both coals we observe that complete devolatilization and burn-out occurs within $1.5 \mathrm{~m}$ from the burner. Furthermore, a large volume of the furnace within this devolatilization and burnout region consists of a mixture of char and ash particles with significantly different radiative properties (Table 1). Since this region also corresponds to the highest flame temperature and therefore radiative heat fluxes, these variations between the char and ash radiative properties must be accounted for if the particle radiation is deemed to be important in

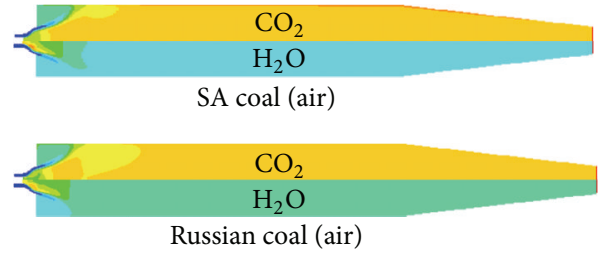

$\begin{array}{lllllllllll}0.00 & 0.02 & 0.04 & 0.06 & 0.08 & 0.10 & 0.12 & 0.14 & 0.16 & 0.18 & 0.20\end{array}$

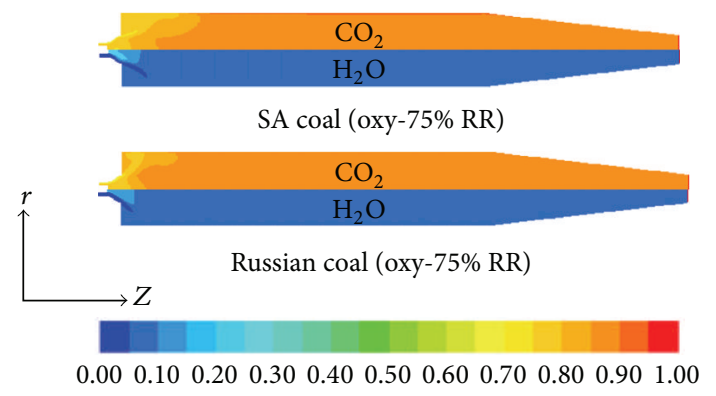

Figure 3: Contours of $\mathrm{CO}_{2}$ and $\mathrm{H}_{2} \mathrm{O}$ mole fractions during the combustion of Russian and SA coal in air and in the oxy-75\% RR scenario (varying particle radiative properties).

this region. Although the contours in Figure 4 are largely identical for combustion in both air and oxy-combustion, differences in the devolatilization and burnout characteristics are observed in the recirculation zone near the burner. Since the temperature in this recirculation zone (circled regions) is generally lower (Figure 2), this can impact the devolatilization and burnout characteristics particularly in the oxy-combustion scenario.

Figure 5 shows the contours of particle concentrations during the combustion of Russian and SA coals. Since 


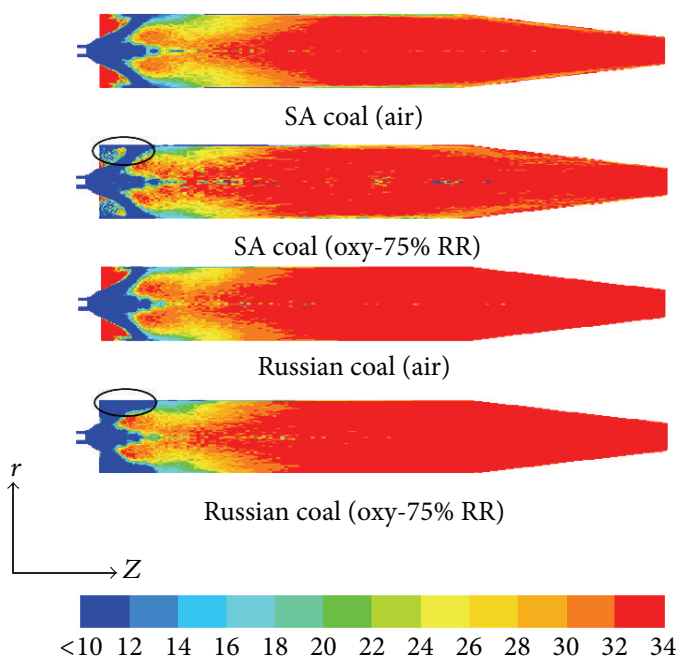

FIgURE 4: Contours of particle scattering coefficient to particle absorption coefficients $\left(\sigma_{p} / k_{p}\right)$ computed by using varying radiative properties for the combusting particle. Differences in the ignition and burnout predictions are seen in the recirculation zone in the oxy-75\% RR scenarios as indicated by circles when compared against combustion in air.
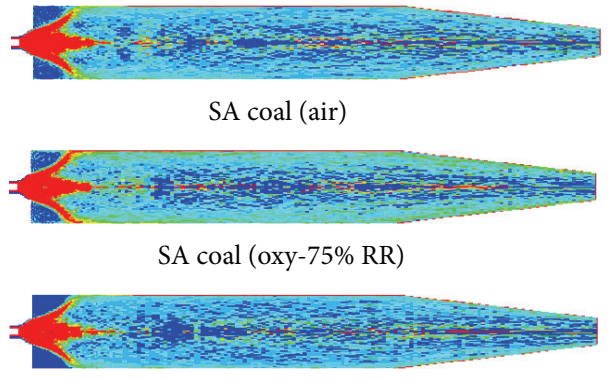

Russian coal (air)

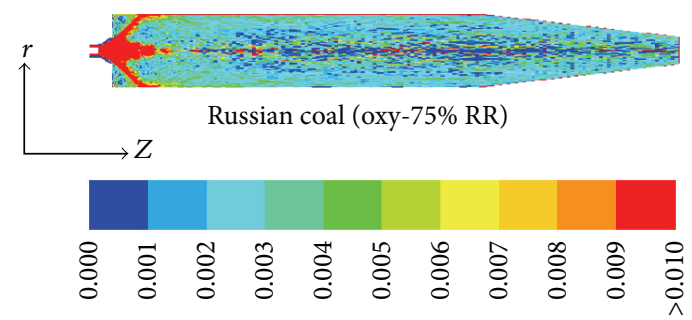

FIGURE 5: Contours of particle concentrations (in $\mathrm{kg} / \mathrm{m}^{3}$ ) during the combustion of Russian and SA coal in air and in the oxy-75\% RR scenario.

the particles are tracked in a Lagrangian reference frame and the particle concentrations are proportional to the residence time within a computational cell and therefore to the velocities and volumetric flow rates of the gas within the furnace, the oxy-combustion scenario clearly results in larger particle concentrations due to the lower volumetric flow rates of the flue gas circulating within this furnace. Since the particle radiative properties are directly proportional to the particle concentrations $((6)$ and (7)), the contours of particle extinction coefficients $\left(\sigma_{p}+k_{p}\right)$ in Figure 6 show higher values associated with the oxy-combustion scenario.

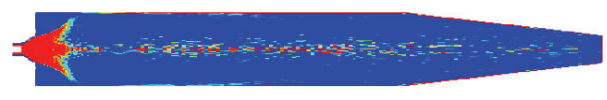

SA coal (air)

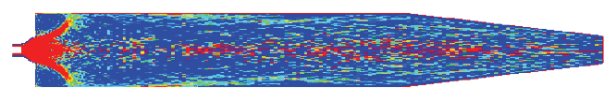

SA coal (RR 75\%)

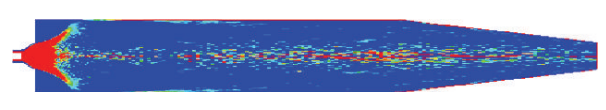

Russian coal (air)

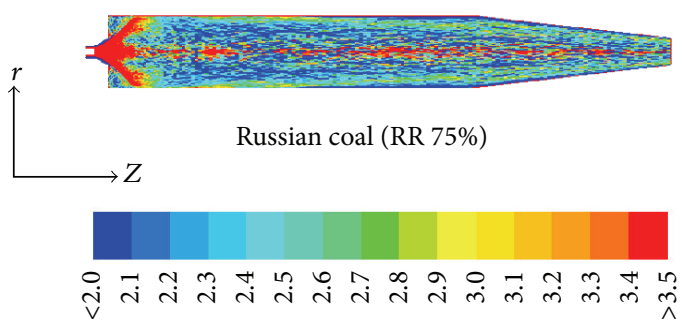

FigURE 6: Contours of particle extinction coefficients $\left(\sigma_{p}+k_{p}\right)$ (in $\mathrm{m}^{-1}$ ) during the combustion of Russian and SA coal in air and in the oxy-75\% RR scenario.

Figure 6 also shows that there are significant variations in the extinction coefficients within the furnace as well as between operating conditions and therefore an assumption of a single constant extinction coefficient cannot be made a priori and is likely to result in incorrect predictions.

Figure 7 shows profiles of incident radiative fluxes during the combustion of the Russian and SA coals. Although reasonable agreement is seen between the experimental measurements and simulation predictions, there are significant variations between the constant and variable particle radiative property predictions. The constant radiative property predictions overestimate the absorption efficiencies and particle emissivities (4) in the high temperature regions containing a mixture of char and ash particles resulting in higher incident radiative fluxes. It is worth noting that it is not uncommon to employ a constant particle emissivity greater than 0.6 throughout the domain in CFD simulations of coal combustion $[15,23]$. Due to the lower temperatures encountered in the $75 \%$ RR scenario, the corresponding incident radiative fluxes are lower than those encountered during combustion in air. While the numerical predictions are generally greater than the experimental measurements, the predictions in the 75\% RR scenarios are lower than the measurements in the near-burner region. This is a result of the inability of the combustion model to predict char ignition characteristics in the recirculation zone (circled regions in Figure 4). This overestimation of the local particle emission when employing constant radiative properties also results in cooling the flame by decreasing the value of the radiative source term (since " $-\nabla \cdot \mathbf{q}(\mathbf{r})$ " is a source term in the temperature/enthalpy equation). This explains the slightly cooler flames observed in Figure 2 with the constant particle radiative property simulations when compared against the varying radiative property simulations. These effects are 


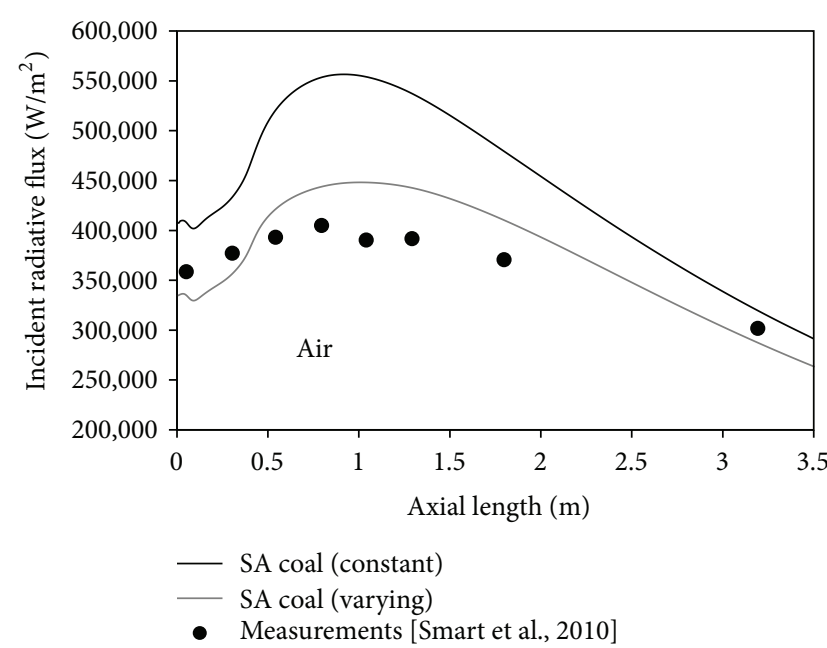

(a)

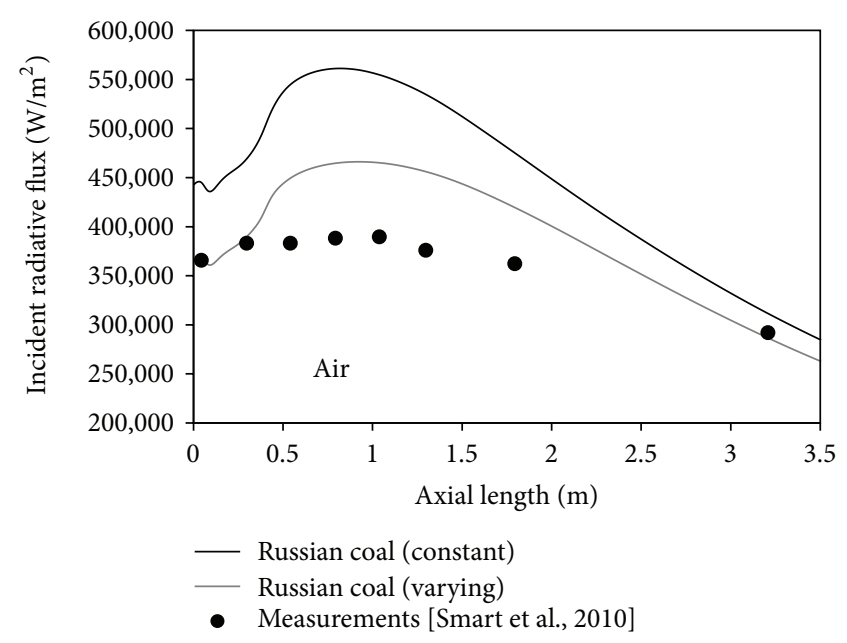

(c)

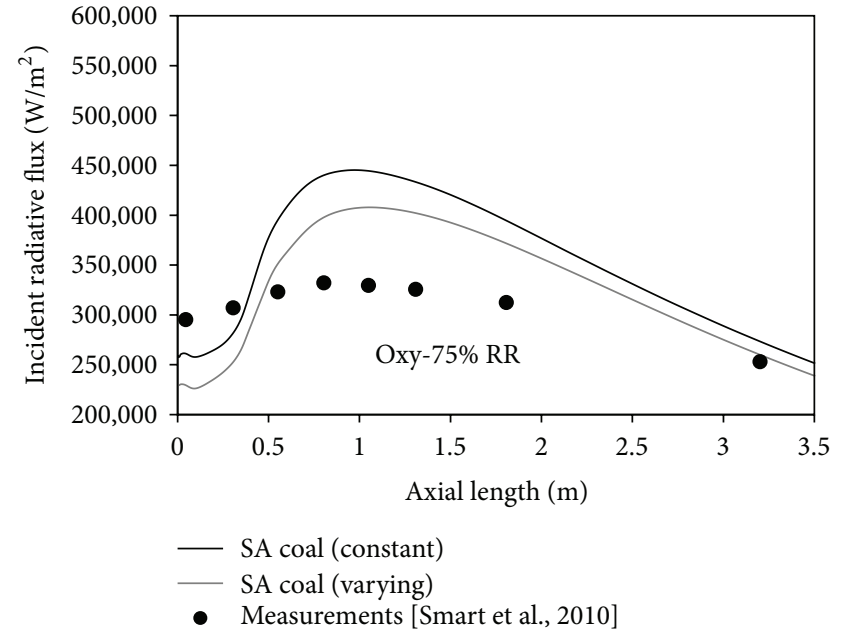

(b)

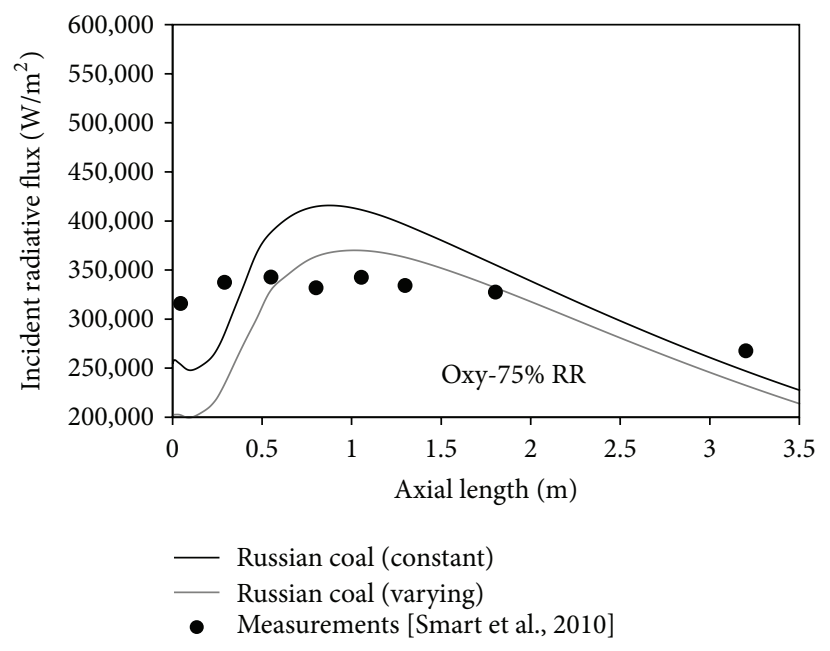

(d)

FIGURE 7: Wall incident radiative flux profiles predicted during the combustion of Russian and SA coals in air and in the oxy-75\% RR scenario. Prediction sensitivities for employing "constant" and "varying" radiative properties are shown.

further quantified in Table 3 where the observed average incident radiative fluxes along the furnace wall are higher and the furnace temperatures are lower when employing the constant radiative properties. These differences are slightly minimized in the "oxy-75\% RR" scenario due to the slightly lower flame temperatures as well as due to the increased contribution of gas radiation.

In Table 3, the net radiative flux which is the difference between the incident radiative flux and the wall emission is seen to be nearly identical in all four scenarios. It is important to recall that, due to the convective boundary conditions imposed at the wall in this study, an increase in incident radiative flux results in an increase in wall temperature which in turn increases the wall emission. Therefore, any increase in incoming radiation at the wall approximately cancels out with a corresponding increase in the outgoing radiation thereby resulting in a constant net radiative flux. However, the total net radiative flux reported in Table 3 is also a measure of the total heat loss due to radiation from the flames. Considering that the total thermal input of the flames is $500 \mathrm{~kW}$, the radiant fraction (total radiative heat loss/thermal input) of these flames is more than 0.4. Therefore, large errors or differences arising in the radiative transfer calculations (such as the radiative source term) will have strong bearing on the incident radiative fluxes as well as the temperature predictions (as shown in Figures 2 and 7).

3.2. Sensitivity to Particle Radiative Property during CoalBiomass Co-Combustion. Figure 8, shows the temperature contours during the co-combustion of Russian coal and biomass in air. The weight $\%$ of the biomass particles in the fuel while maintaining a constant thermal input of $0.5 \mathrm{MW}$ is also indicated. Increasing the mass fraction of the biomass particles decreases the temperature within the furnace. The moisture content of the SA coal, Russian coal, Shea meal, and 
TABLE 3: Radiation and temperature predictions during coal combustion.

\begin{tabular}{|c|c|c|c|c|c|c|c|}
\hline \multirow[b]{2}{*}{ Fuel } & \multirow[b]{2}{*}{ Combustion mode } & \multicolumn{2}{|c|}{ Net radiative flux $(\mathrm{kW})$} & \multicolumn{2}{|c|}{ Average incident radiative flux $\left(\mathrm{W} / \mathrm{m}^{2}\right)$} & \multicolumn{2}{|c|}{ Average furnace temperature $(\mathrm{K})$} \\
\hline & & $\begin{array}{l}\text { Constant } \\
\text { property }\end{array}$ & $\begin{array}{l}\text { Variable } \\
\text { property }\end{array}$ & $\begin{array}{l}\text { Constant } \\
\text { property }\end{array}$ & $\begin{array}{l}\text { Variable } \\
\text { property }\end{array}$ & $\begin{array}{l}\text { Constant } \\
\text { property }\end{array}$ & $\begin{array}{l}\text { Variable } \\
\text { property }\end{array}$ \\
\hline SA coal & Air firing & 222 & 204 & 363 & 313 & 1631 & 1666 \\
\hline SA coal & Oxy-75\% RR & 215 & 210 & 296 & 277 & 1570 & 1578 \\
\hline Russian coal & Air firing & 227 & 214 & 363 & 320 & 1643 & 1676 \\
\hline Russian coal & Oxy-75\% RR & 210 & 203 & 273 & 249 & 1533 & 1542 \\
\hline
\end{tabular}
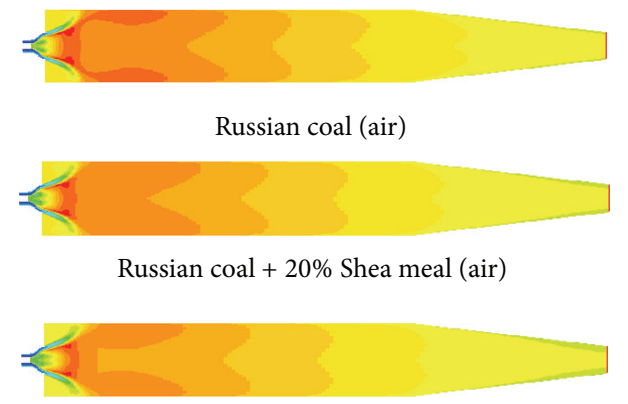

Russian coal $+40 \%$ Shea meal (air)

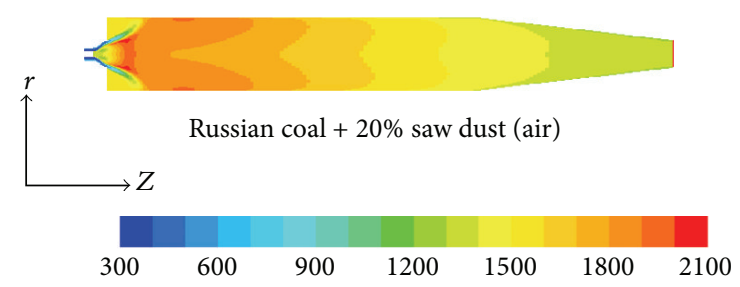

FIGURE 8: Temperature contours during the co-combustion of Russian coal and biomass particles in air.

saw dust was $4.50 \%, 6.23 \%, 11.58 \%$, and $30.00 \%$, respectively. The higher moisture content and the lower calorific value of the biomass particles suppress the flame temperatures.

Figure 9 shows the contours of incident radiative heat fluxes in the Russian coal-biomass cofiring scenarios in air with the calculations performed with variable particle radiative properties for both the coal and biomass particles (Table 1). A reasonable agreement is seen between the experimental measurements and the simulation predictions with the trends reflective of the temperature predictions; that is, increasing the mass fraction of the biomass particles in the feed decreases the incident radiative fluxes. Saw dust by virtue of its higher moisture content and lower calorific value when compared to Shea meal results in lowering the flame temperatures and incident radiative fluxes even more for the same mass fraction in the feed. In Figure 9(b), the sensitivities of the predictions to the biomass devolatilization models employed in the simulations were assessed. Since the default devolatilization modeling option (two competing rates (Kobayashi) model) was developed more for coal combustion scenarios, a constant devolatilization rate of $20 \mathrm{~s}^{-1}$ was also employed in the simulations. The incident radiative flux predictions were found to be largely insensitive to the biomass devolatilization model employed in the simulations as seen in Figure 9(b).

Figure 10 compares the incident radiative flux predictions during the cofiring of SA coal and Shea meal employing constant radiative properties (corresponding to the coal char and biomass char in Table 1) and variable radiative properties for both the coal and biomass particles. Similar to the observations in the coal combustion scenario (Figure 7), there are considerable variations in the incident radiative flux predictions between the two property models. Employing a constant radiative property corresponding to that of the fuel char can therefore lead to a considerable overestimation of the incident radiative fluxes.

Apart from the variability in the absorption and scattering efficiencies of the combusting particle, there can also be a great deal of variability in the scattering phase functions ( $\Phi$ in (2)) of the combusting particle. The scattering phase function is strongly dependent on the particle size as well as shape [5]. Both coal and biomass particles have irregular shapes which can change further resulting from fragmentation during the combustion process. While experimental observations have confirmed that coal particles are highly forward scattering [5], there can be considerable variability in the scattering phase function. Furthermore, as noted in Table 1 and Figure 4, the particle scattering coefficients of the ash particles are much higher than the absorption coefficients. Therefore, in order to assess the sensitivity to the scattering phase function, a simulation with isotropic scattering phase function was carried out in addition to the highly forward scattering diracdelta phase function that was employed in all of the simulations. The predictions are compared in Figure 11 during the combustion of Russian coal during "oxy-75\% RR." The results indicate very little sensitivity to the scattering phase function characteristics of the particles. These observations regarding scattering in coal-fired furnaces are similar to those reported in a previous study in a nearly identical sized furnace for combustion in air [24]. In that study, neglecting scattering altogether was suggested as a preferred alternative to isotropic scattering when neglecting the strongly forward scattering behavior of coal particles becomes necessary to reduce the computational effort. However, since "oxy-75\% RR" scenario was explored in this study, despite the increase in particle concentrations and scattering coefficients, the increased importance of gas radiation likely suppressed further any 


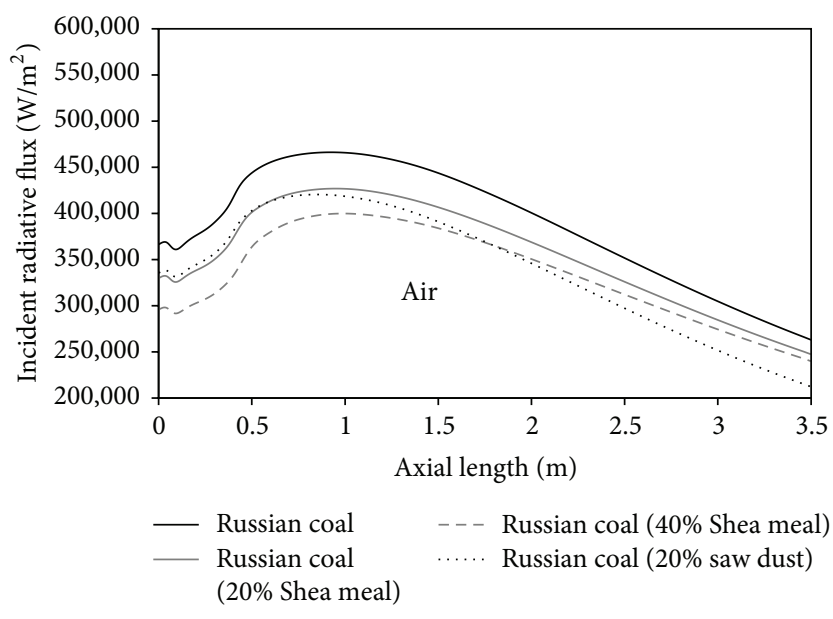

(a)

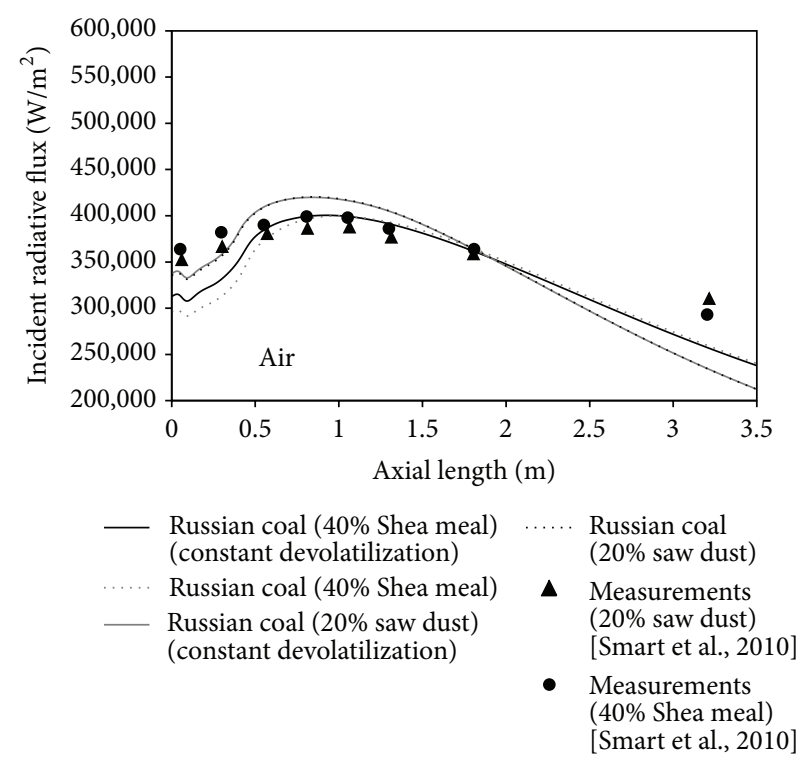

(b)

FIGURE 9: Wall incident radiative flux profiles predicted during the co-combustion of Russian coal and biomass particles in air.

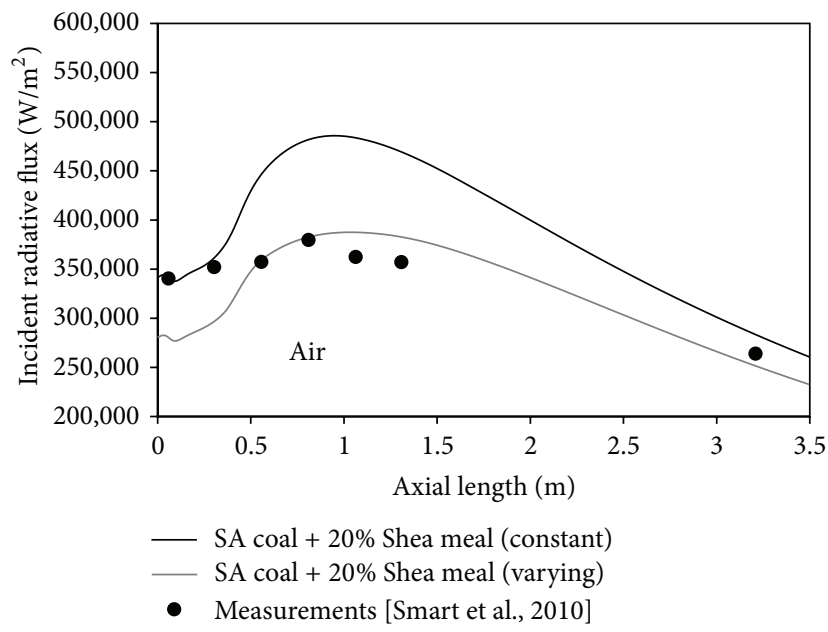

(a)

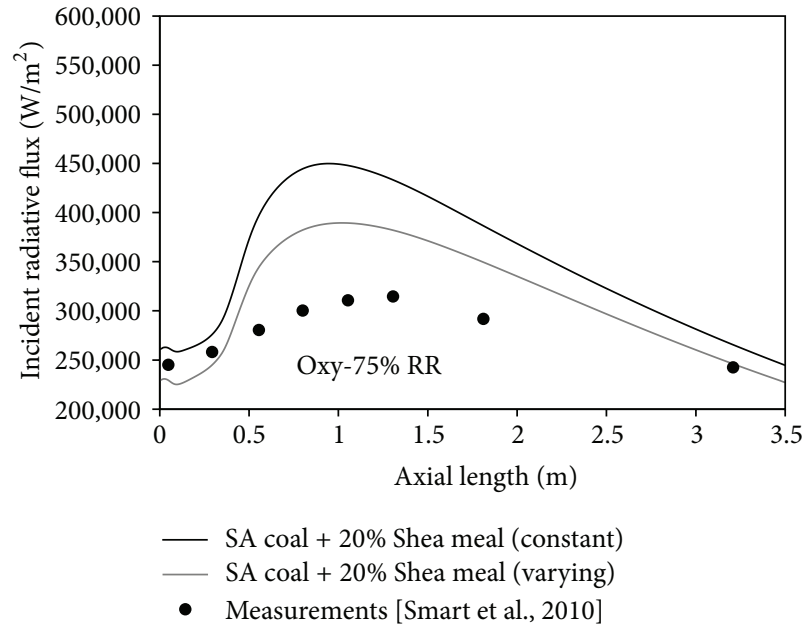

(b)

FIGURE 10: Wall incident radiative flux profiles predicted during the co-combustion of SA coal and biomass particles in air and oxy-75\% RR.

prediction differences arising due to the scattering phase function. This is confirmed in Table 4 where the total radiant powers of the different flames (estimated by employing variable particle radiative properties in the simulations) are reported. This was computed as the surface integral of the net radiative heat fluxes through all the boundaries of the geometry or alternatively as the volume integral of the radiative source term within the furnace. In order to assess the individual contributions of gas and particulates to the total radiant power, the converged temperature and specie concentrations were "frozen," particle radiative properties were set to zero and the radiation field recomputed along with the volume integral of the radiative source term. This new radiant power which accounts for gas radiation alone is also reported in Table 4. Gas radiation accounts for 60$70 \%$ of the total radiant power during combustion in air and more than $80 \%$ of the total radiant power during oxycombustion. However, in the near burner region, particle radiation can dominate and the choice of particle radiative properties can greatly impact the accuracies of the incident radiative flux predictions as shown in Figures 7 and 10. This becomes particularly important when numerical prediction accuracies are assessed against radiometric measurements. It is also important to note that the values of radiant power reported in Table 4 may be slightly different from the values of the net radiative fluxes reported in Table 3 due to the fact that the radiant power estimates were made by accounting for radiative transfer through all boundaries (including inlets 


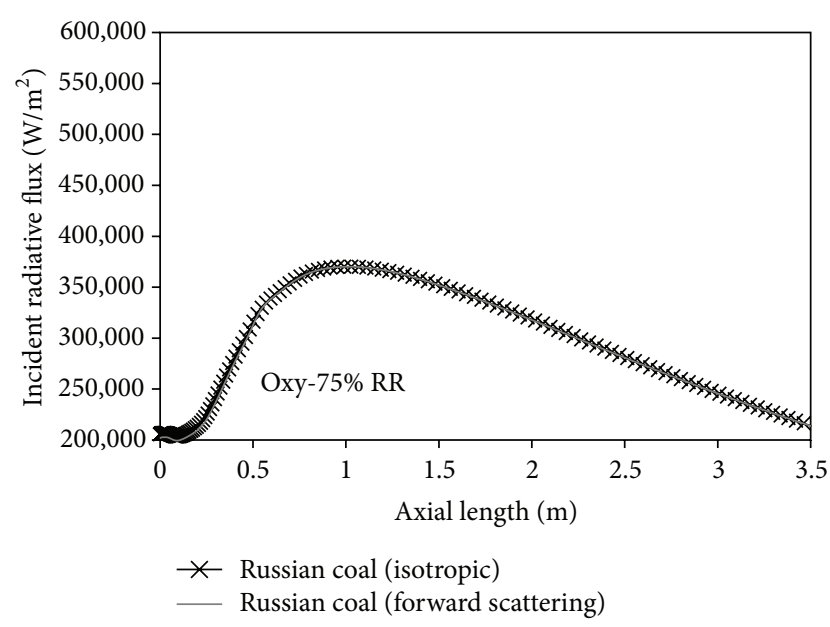

FIGURE 11: Sensitivity to scattering phase function during the combustion of Russian coal during oxy-75\% RR.

and outlets) whereas the net radiative fluxes were estimated only along the horizontal walls of the furnace aligned along the axial direction.

3.3. Sensitivity to Particle Size Predictions. While the discussion so far has focused on the variability in the particle radiative properties during the combustion process, the absorption and scattering coefficients are also proportional to the particle diameter squared through its dependence on the projected surface area (" $A_{\mathrm{pn}}$ " in (6) and (7)). Therefore, even modest changes to the particle diameter through swelling and fragmentation during the combustion process may translate to large changes to the absorption and scattering coefficients, the incident radiative flux predictions. In fact, accurate modeling of char fragmentation during burnout has been emphasized as one of the pressing modeling needs not only for radiative transfer but also for carbon-in-ash predictions [25]. One of the theories explaining char fragmentation attributes it to changes to the particle porosity that may result from swelling during the combustion process. Therefore, a swelling factor is also commonly employed in CFD simulations of coal and biomass combustion [26]. Although char fragmentation was not modeled in this study, a set of simulations were carried out employing a swelling factor of 1.5 (which increases the particle absorption coefficient by factor of 2.25). The incident radiative flux predictions are compared in Figure 12. In both combustion in air and $75 \%$ RR scenario, particle swelling is observed to have an effect on the incident radiative flux profiles as well as on the location of the peak incident radiative fluxes. Therefore, modeling of swelling and fragmentation during the fuel burnout are deemed to be important for obtaining accurate estimates of radiative transfer.

A second size distribution parameter that was investigated in this study was the number of diameter bins employed in the Rosin-Rammler (RR) size distribution shown in Figure 1. Although the PSD is identical for a given twoparameter RR distribution, it is important to ascertain that adequate resolution (or diameter intervals) is employed in the simulations as there can be some variability in the fraction of mass that is distributed to the different diameter sized particles depending on the number of bins employed. This becomes particularly important when dealing with fuels encompassing a large size range. However, since the computational cost of the Lagrangian particle tracking calculation is directly proportional to the number of bins employed, 6 to 10 bins in RR distribution are generally deemed to be adequate $[23,27]$.

To investigate the sensitivity to the resolution of the $\mathrm{RR}$ distribution, additional simulations were carried out employing 40 bins in the RR distribution. The mass fraction distributions to different particle sizes for particles sampled at the outlet are shown in Figure 13. Since the diameter of the combusting particles in these simulations did not undergo any changes due to swelling/fragmentation, the reported results should have been independent of the number of diameter intervals employed for the fuel PSD at the inlet. While this is largely true when considering the entire size range of the particles (left side images of Figure 13), a closer examination of the larger sized particles reveals that the particle mass fraction distribution in the larger sized particles (which carry the majority of the particle mass) can vary significantly depending on the number of diameter intervals employed at the inlet. This can in turn affect the particle concentration distributions and the particle extinction coefficients and consequently the incident radiative fluxes. The prediction sensitivities of the particle extinction coefficients to the diameter intervals are shown in Figure 14. Since employing fewer diameter intervals overestimate the fraction of mass that is distributed to the larger sized particles (Figure 13), they also overestimate the large particle number densities and concentrations and consequently the particle extinction coefficients as shown in Figure 14. This has an impact on the incident radiative flux predictions as shown in Figure 15. Any further increase in the number of diameter intervals (beyond 40) did not have an effect on the simulation predictions in this study. This again points to the criticality of developing appropriate fragmentation models as even small differences in the mass fractions in the larger sized particles (which carry most of the mass of the fuel particles) can have a big impact on the radiative transfer predictions.

Figure 16 examines the impact on particle swelling and diameter intervals on the temperature predictions within the furnace. While a minimal impact is seen on the temperature field, the differences are not as pronounced as seen in Figure 2 (between the constant and varying radiative property predictions). This indicates that any differences in the radiative source term predictions due to swelling, fragmentation, or the mass distributions in the larger sized particles are likely to be small to have a significant impact on the temperature field but they can influence the incident radiative flux predictions.

\section{Conclusions}

To facilitate the retrofitting of existing coal-fired boilers to oxy-combustion scenarios requires an improved 
TABLE 4: Radiant power of the different flames estimated by employing variable particle radiative properties in the simulations.

\begin{tabular}{lccc}
\hline Fuel & Combustion mode & Radiant power (kW) & $\begin{array}{c}\text { Radiant power (kW) } \\
\text { (gas radiation only) }\end{array}$ \\
\hline SA Coal & Air firing & 211 & 141 \\
SA Coal & Recycle 75 & 209 & 183 \\
SA + 20\% Shea meal & Air firing & 202 & 138 \\
SA + 20\% Shea meal & Recycle 75 & 201 & 168 \\
Russian coal & Air firing & 222 & 145 \\
Russian coal & Recycle 75 & 207 & 175 \\
Russian coal $+20 \%$ Shea meal & Air firing & 215 & 145 \\
Russian coal $+40 \%$ Shea meal & Air firing & 210 & 146 \\
Russian coal $+20 \%$ saw dust & Air firing & 204 & 133 \\
\hline
\end{tabular}

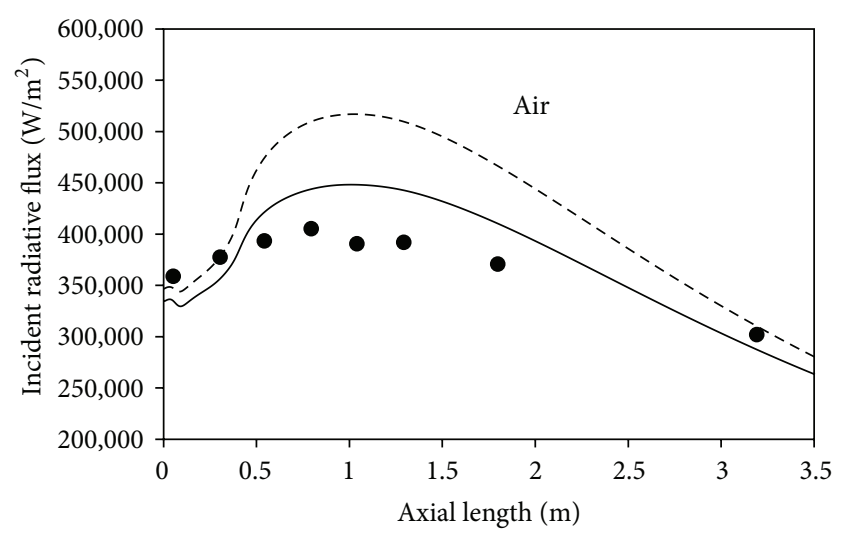

— SA coal (without particle swelling)

- - SA coal (particle swelling)

- Measurements [Smart et al., 2010]

(a)

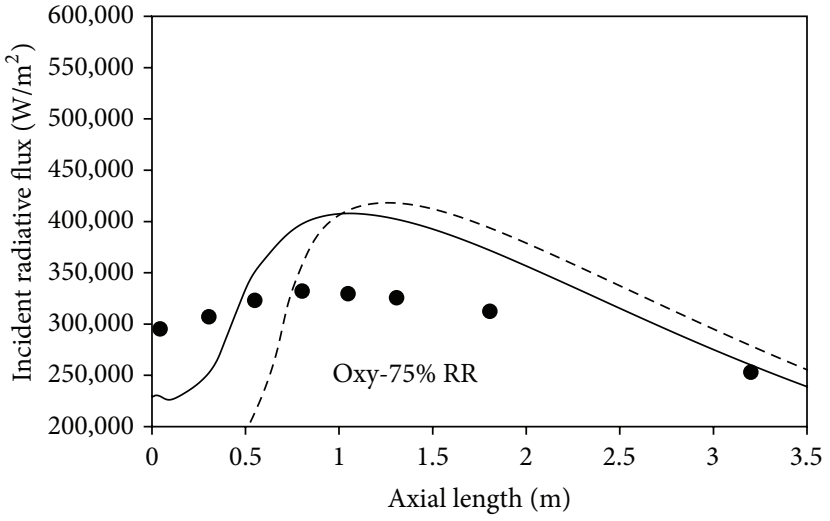

— SA coal (without particle swelling)

- - SA coal (particle swelling)

- Measurements [Smart et al., 2010]

(b)

FIGURE 12: Sensitivities of the incident radiative fluxes to particle swelling during combustion of SA coal.

understanding of the role of particle radiation, its contribution relative to that of the radiatively participating gases within the boiler, and how it is influenced by the evolving fly ash particle size distributions (PSDs) under these newer operating conditions. By taking advantage of recent radiative transfer measurements made in a $0.5 \mathrm{MW}$ combustion test facility during combustion of coal-biomass blends under air-fired and oxy-fired conditions, this study assesses the need for and the required fidelity in modeling the evolving PSD and radiative properties of the combusting particles as a function of residence time within the boiler. Two different coals (a South African and a Russian) that were blended with two types of biomass particles (Shea meal and saw dust) were investigated during combustion in air and oxy-combustion at a flue gas recycle ratio of $75 \%$. The fuel and oxidizer compositions were varied to maintain a target exit $\mathrm{O}_{2}$ concentration of $3 \mathrm{~mol} \%$ (dry basis) in all of the investigated scenarios. The sensitivities of the radiation predictions to the variations in the radiative properties of the combusting particle (absorption and scattering efficiencies), particle swelling during devolatilization, particle scattering phase function, biomass devolatilization models, and the resolution of the fuel PSD were assessed. The following conclusions may be drawn from the results of this study:

(1) While reasonable agreement with experimental measurements was observed in the investigated scenarios, accounting for the significant variations in the radiative properties (absorption and scattering efficiencies) between the parent fuel, combusting char, and ash particles was deemed important towards improving the prediction accuracies. This was due to the fact that a large volume of the furnace near the radiation measurement locations consisted of combusting char and ash particle mixtures and therefore an assumption of a constant radiative property (corresponding to that of char or the ash) throughout the furnace could result in inaccurate predictions. These variations in the particle radiative properties strongly influenced the incident radiative fluxes as well as the temperature predictions in these strongly radiating flames (which had radiant fractions $>0.4$ ). 


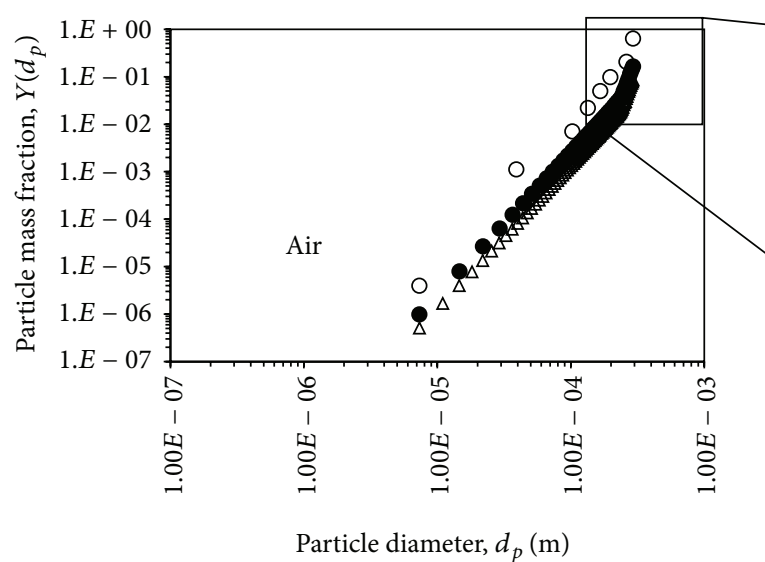

- 8 diameters

- 40 diameters

$\triangle 80$ diameters

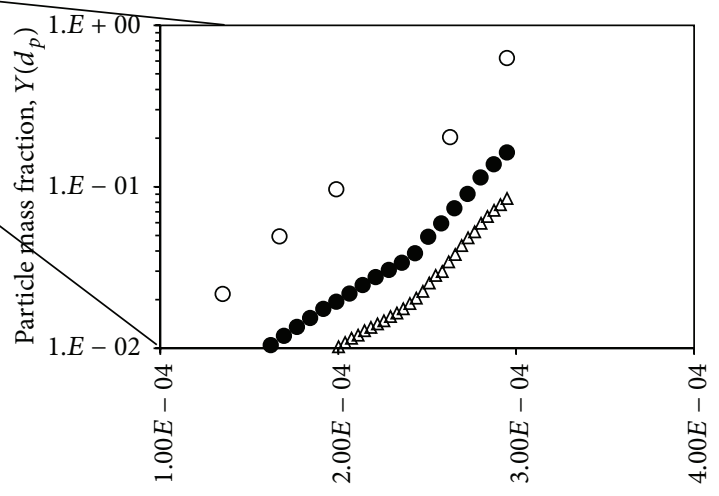

Particle diameter, $d_{p}(\mathrm{~m})$

○ 8 diameters

- 40 diameters

$\triangle 80$ diameters

(a)

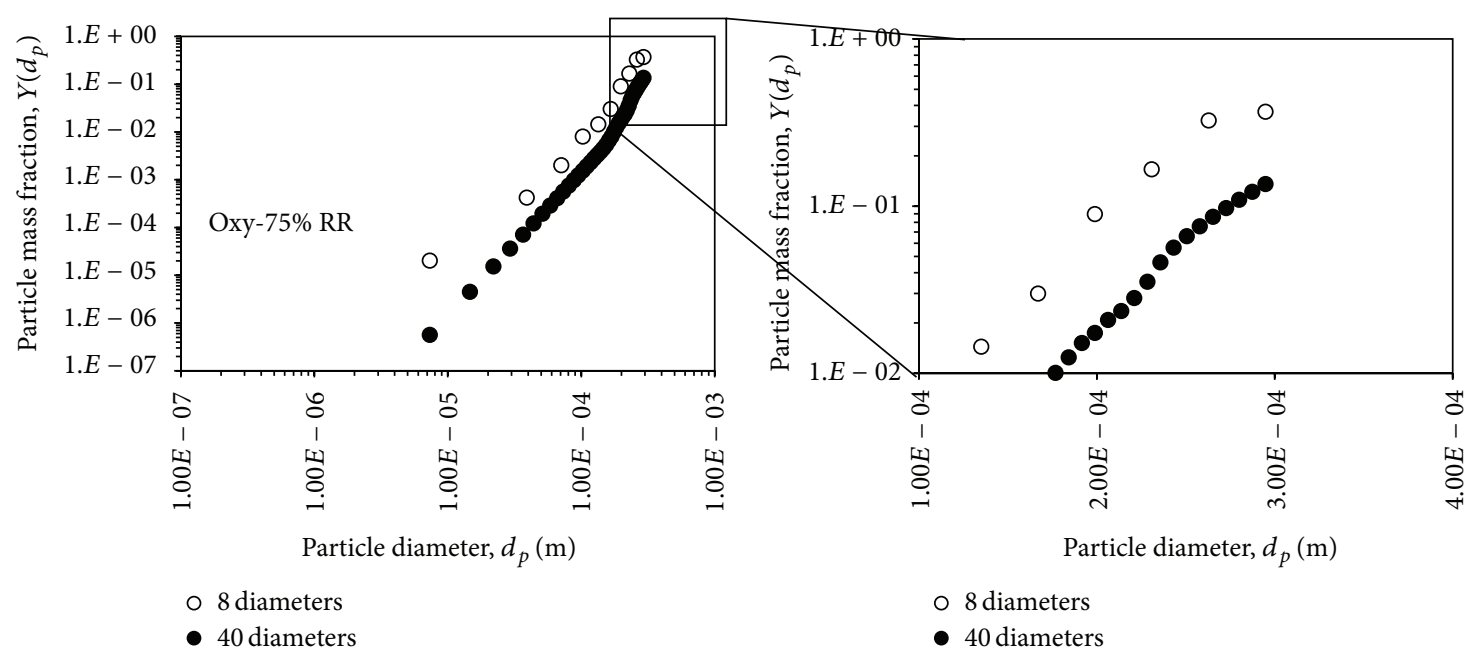

(b)

FIGURE 13: Sensitivities of the mass fraction distribution to different particle sizes as a function of the number of diameter intervals (or resolution in the R-R distribution) during combustion of Russian coal.

(2) The lower gas flow rates through the furnace during oxy-combustion resulted in higher particle concentrations and particle extinction coefficients when compared against combustion in air. However, the $75 \%$ recycle ratio that was investigated in this study resulted in lower gas and particle temperatures which slightly minimized the differences between the constant particle radiative property predictions and the predictions employing variable particle radiative properties when compared to combustion in air. In addition, the increased contribution of gas radiation in the recycle scenario could have also contributed to this minimization.

(3) Although all the inlet fuel particle size distributions were fit to a Rosin-Rammler (RR) distribution function, the resolution or the diameter intervals employed in the RR function and particle swelling during devolatilization had an impact on the particle extinction coefficients as well as the incident radiative flux predictions. On the other hand, the impact of variations in these parameters on the temperature field was minimal.

(4) Although the modeled scattering efficiencies of particles were significantly larger than their absorption efficiencies, both isotropic and forward scattering phase functions resulted in identical radiative flux profiles. Therefore, any change to the scattering phase function due to the evolving size and shape of the fly ash particle as it moves through the furnace is likely to have a minimal impact on the furnace radiative transfer at these high temperatures. Therefore, it is recommended that the highly forward scattering characteristics attributed to spherical char and ash 


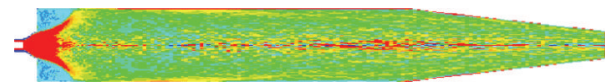

Russian coal (air), 8 diameters

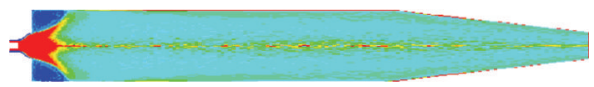

Russian coal (air), 40 diameters

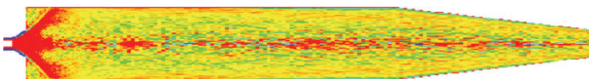

Russian coal (oxy-75\% RR), 8 diameters

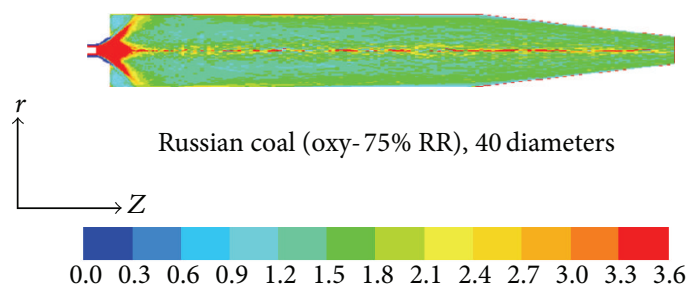

FIgURE 14: Sensitivities of the particle extinction coefficients $\left(\sigma_{p}+k_{p}\right)\left(\right.$ in $\left.^{-1}\right)$ to the number of diameter intervals (or resolution in the R-R distribution) during combustion of Russian coal.

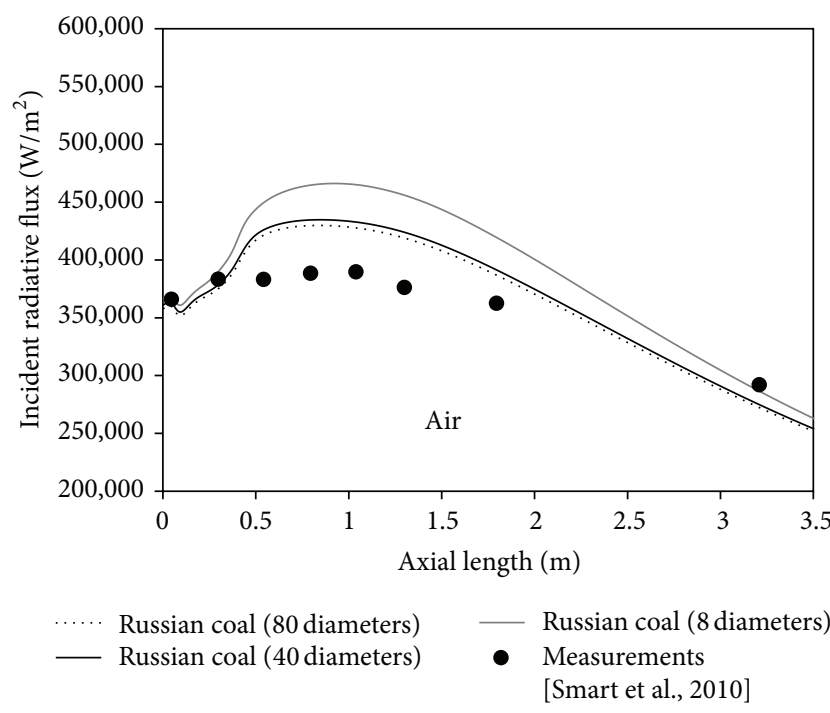

(a)

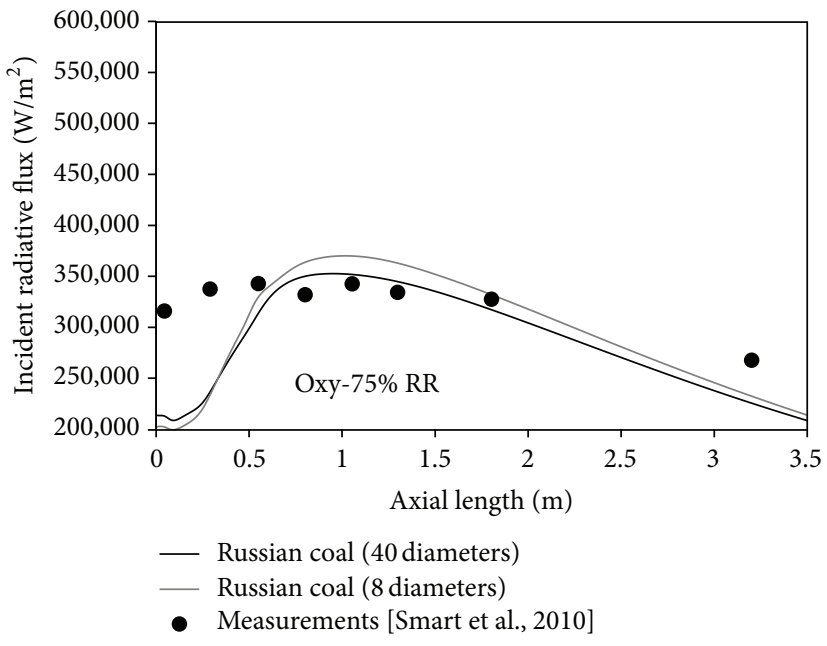

(b)

FIGURE 15: Sensitivities of the incident radiative fluxes to the number of diameter intervals (or resolution in the R-R distribution) during combustion of Russian coal.

particles can be applied in these scenarios without too much loss in accuracy.

(5) Although the fuel heating value was maintained at $0.5 \mathrm{MW}$ in the biomass-coal cofiring scenarios as well, the gas temperatures and consequently the wall incident radiative fluxes both decreased with an increase in mass of biomass in the feed due to the higher moisture content and lower calorific values of the biomass particles. The choice of biomass devolatilization models did not significantly impact the predictions in this study since the devolatilization was completed at short residence times from the burner.

This study therefore highlights the necessity for careful selection of particle radiative property and diameter interval parameters in CFD simulations of coal/biomass combustion and the need for fuel fragmentation models to adequately predict the fly ash PSD. 


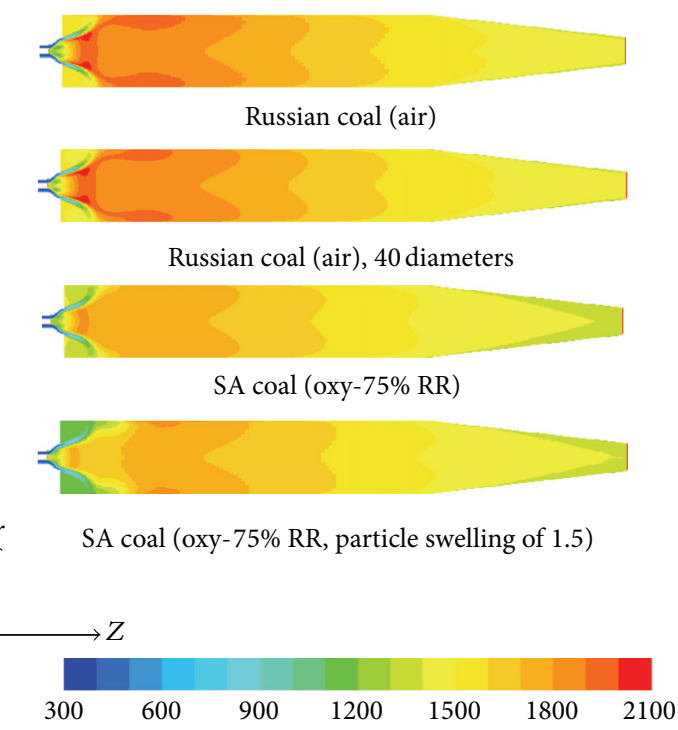

FIgURE 16: Sensitivities of the temperature contours to particle swelling and diameter intervals during coal combustion.

\section{Conflict of Interests}

The authors declare that there is no conflict of interests regarding the publication of this paper.

\section{Acknowledgment}

This work was partially supported by a grant to Ms. Caitlyn Wolf administered through the North Dakota EPSCoR's Advanced Undergraduate Research Awards (AURA) program.

\section{References}

[1] R. Viskanta and M. P. Mengüç, "Radiation heat transfer in combustion systems," Progress in Energy and Combustion Science, vol. 13, no. 2, pp. 97-160, 1987.

[2] M. F. Modest, Radiative Heat Transfer, Academic Press, 2013.

[3] H. Hofgren and B. Sundén, "Evaluation of Planck mean coefficients for particle radiative properties in combustion environments," Heat and Mass Transfer, 2014.

[4] D. G. Goodwin and M. Mitchner, "Flyash radiative properties and effects on radiative heat transfer in coal-fired systems," International Journal of Heat and Mass Transfer, vol. 32, no. 4, pp. 627-638, 1989.

[5] M. P. Mengüç, S. Manickavasagam, and D. A. D’Sa, “Determination of radiative properties of pulverized coal particles from experiments," Fuel, vol. 73, no. 4, pp. 613-625, 1994.

[6] R. P. Gupta, T. F. Wall, and J. S. Truelove, "Radiative scatter by fly ash in pulverized-coal-fired furnaces: application of the Monte Carlo method to anisotropic scatter," International Journal of Heat and Mass Transfer, vol. 26, no. 11, pp. 1649-1660, 1983.

[7] F. Liu and J. Swithenbank, "The effects of particle size distribution and refractive index on fly-ash radiative properties using a simplified approach," International Journal of Heat and Mass Transfer, vol. 36, no. 7, pp. 1905-1912, 1993.

[8] G. Scheffknecht, L. Al-Makhadmeh, U. Schnell, and J. Maier, "Oxy-fuel coal combustion-a review of the current state-ofthe-art," International Journal of Greenhouse Gas Control, vol. 5, no. 1, pp. S16-S35, 2011.

[9] P. Edge, M. Gharebaghi, R. Irons et al., "Combustion modelling opportunities and challenges for oxy-coal carbon capture technology," Chemical Engineering Research and Design, vol. 89, no. 9, pp. 1470-1493, 2011.

[10] R. Johansson, K. Andersson, B. Leckner, and H. Thunman, "Models for gaseous radiative heat transfer applied to oxy-fuel conditions in boilers," International Journal of Heat and Mass Transfer, vol. 53, no. 1-3, pp. 220-230, 2010.

[11] G. Krishnamoorthy, "A new weighted-sum-of-gray-gases model for oxy-combustion scenarios," International Journal of Energy Research, vol. 37, no. 14, pp. 1752-1763, 2013.

[12] C. Yin, L. C. R. Johansen, L. A. Rosendahl, and S. K. Kær, "New weighted sum of gray gases model applicable to computational fluid dynamics (CFD) modeling of oxy-fuel combustion: derivation, validation, and implementation," Energy and Fuels, vol. 24, no. 12, pp. 6275-6282, 2010.

[13] T. Kangwanpongpan, F. H. R. França, R. Corrêa da Silva, P. S. Schneider, and H. J. Krautz, "New correlations for the weightedsum-of-gray-gases model in oxy-fuel conditions based on HITEMP 2010 database," International Journal of Heat and Mass Transfer, vol. 55, no. 25-26, pp. 7419-7433, 2012. 
[14] Y. Hu and J. Yan, "Numerical simulation of radiation intensity of oxy-coal combustion with flue gas recirculation," International Journal of Greenhouse Gas Control, vol. 17, pp. 473-480, 2013.

[15] M. Gharebaghi, R. M. A. Irons, L. Ma, M. Pourkashanian, and A. Pranzitelli, "Large eddy simulation of oxy-coal combustion in an industrial combustion test facility," International Journal of Greenhouse Gas Control, vol. 5, supplement 1, pp. S100-S110, 2011.

[16] L. L. Baxter, "Char fragmentation and fly ash formation during pulverized-coal combustion," Combustion and Flame, vol. 90, no. 2, pp. 174-184, 1992.

[17] N. Syred, K. Kurniawan, T. Griffiths, T. Gralton, and R. Ray, "Development of fragmentation models for solid fuel combustion and gasification as subroutines for inclusion in CFD codes," Fuel, vol. 86, no. 14, pp. 2221-2231, 2007.

[18] J. P. Smart, R. Patel, and G. S. Riley, "Oxy-fuel combustion of coal and biomass, the effect on radiative and convective heat transfer and burnout," Combustion and Flame, vol. 157, no. 12, pp. 2230-2240, 2010.

[19] Fluent, ANSYS, "15.0 Theory Guide”, ANSYS Inc, 2014.

[20] G. Krishnamoorthy, "A new weighted-sum-of-gray-gases model for $\mathrm{CO}_{2}-\mathrm{H}_{2} \mathrm{O}$ gas mixtures," International Communications in Heat and Mass Transfer, vol. 37, no. 9, pp. 1182-1186, 2010.

[21] J. Zhang, T. Ito, S. Ito, D. Riechelmann, and T. Fujimori, "Numerical investigation of oxy-coal combustion in a largescale furnace: non-gray effect of gas and role of particle radiation," Fuel, vol. 139, pp. 87-93, 2015.

[22] K. Kuehlert, Modellbildung und Berechnung der Wärmestrahlung in Gas- und Kohlenstaubfeuerungen [Ph.D. thesis], RWTH Aachen University, Aachen, Germany, 1998.

[23] R. Filkoski, I. Petrovski, and P. Karas, "Optimization of pulverised coal combustion by means of CFD/CTA modeling," Thermal Science, vol. 10, no. 3, pp. 161-179, 2006.

[24] J. G. Marakis, C. Papapavlou, and E. Kakaras, "A parametric study of radiative heat transfer in pulverised coal furnaces," International Journal of Heat and Mass Transfer, vol. 43, no. 16, pp. 2961-2971, 2000.

[25] R. Weber, M. Mancini, N. Schaffel-Mancini, and T. Kupka, "On predicting the ash behaviour using Computational Fluid Dynamics," Fuel Processing Technology, vol. 105, pp. 113-128, 2013.

[26] J. Li, A. Brzdekiewicz, W. Yang, and W. Blasiak, "Co-firing based on biomass torrefaction in a pulverized coal boiler with aim of 100\% fuel switching," Applied Energy, vol. 99, pp. 344-354, 2012.

[27] R. V. Filkoski, "Pulverised-coal combustion with staged air introduction: CFD analysis with different thermal radiation methods," Open Thermodynamics Journal, vol. 4, pp. 2-12, 2010. 

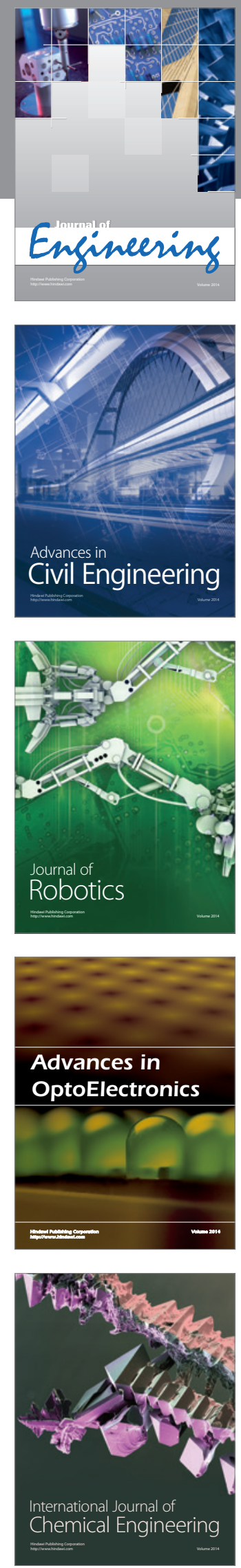

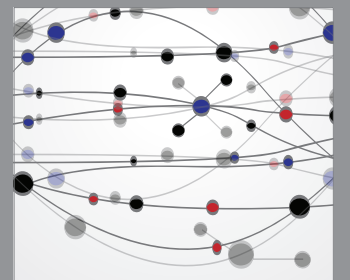

The Scientific World Journal
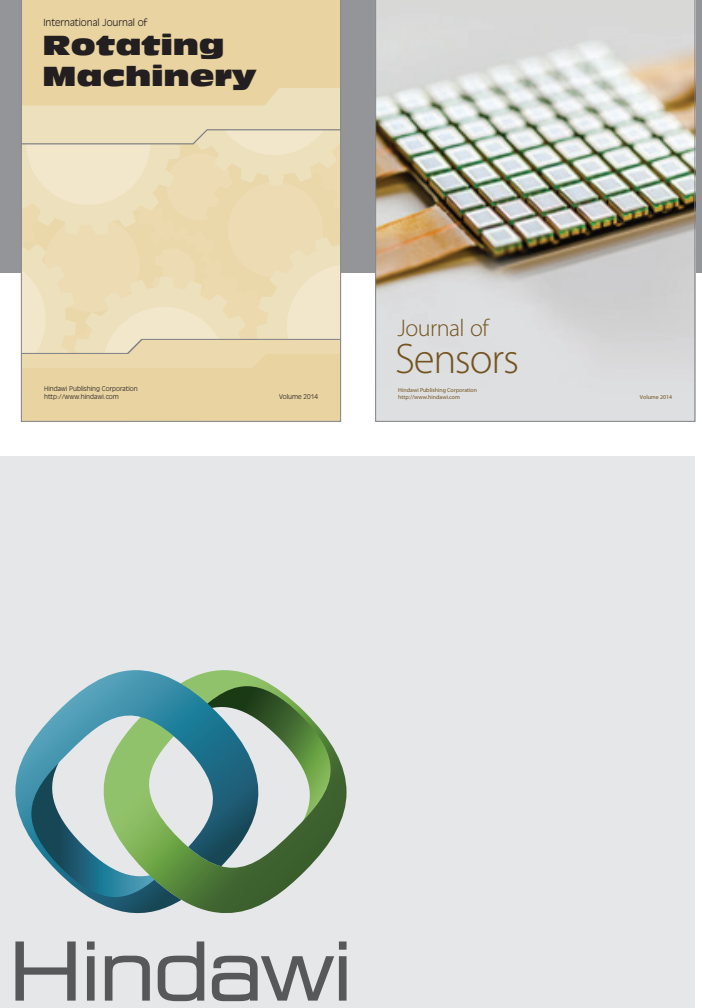

Submit your manuscripts at http://www.hindawi.com
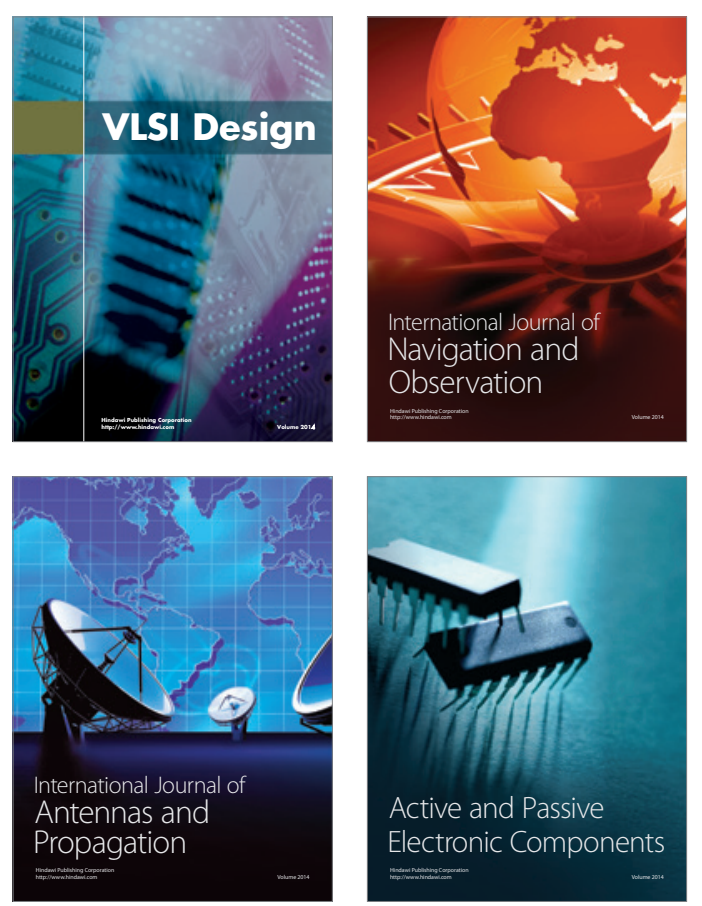
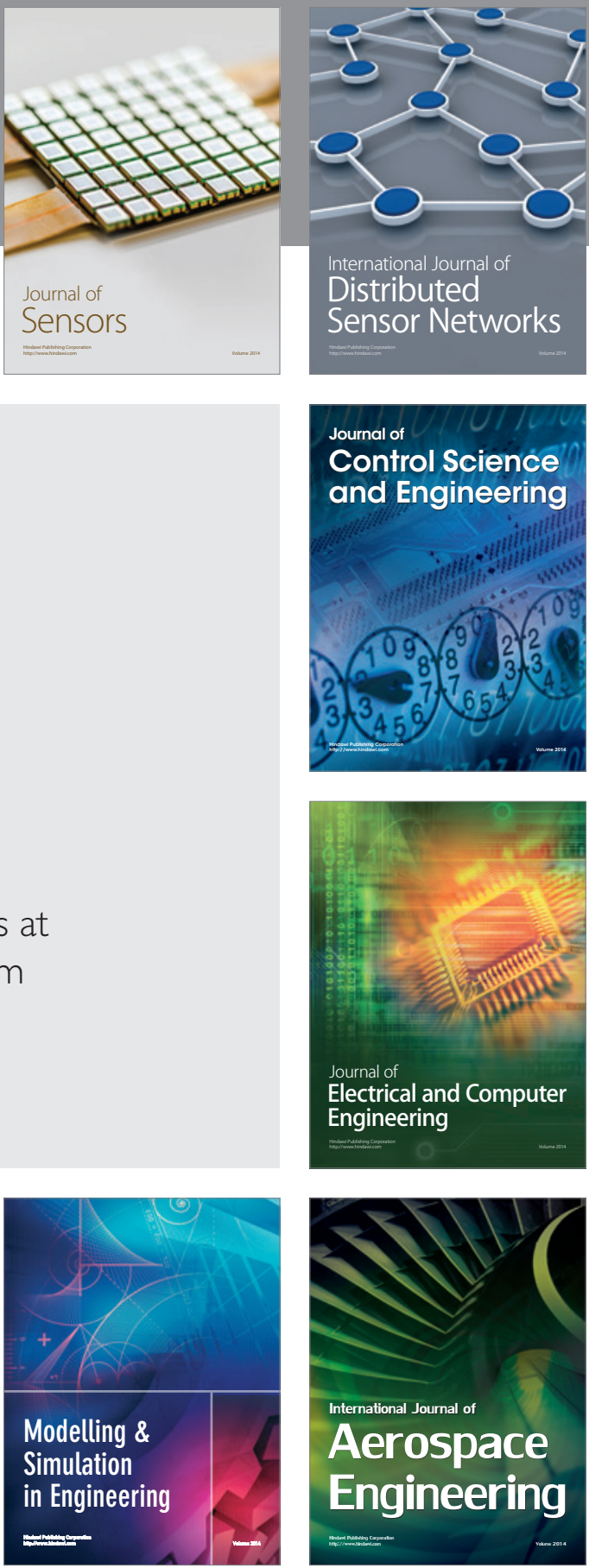

Journal of

Control Science

and Engineering
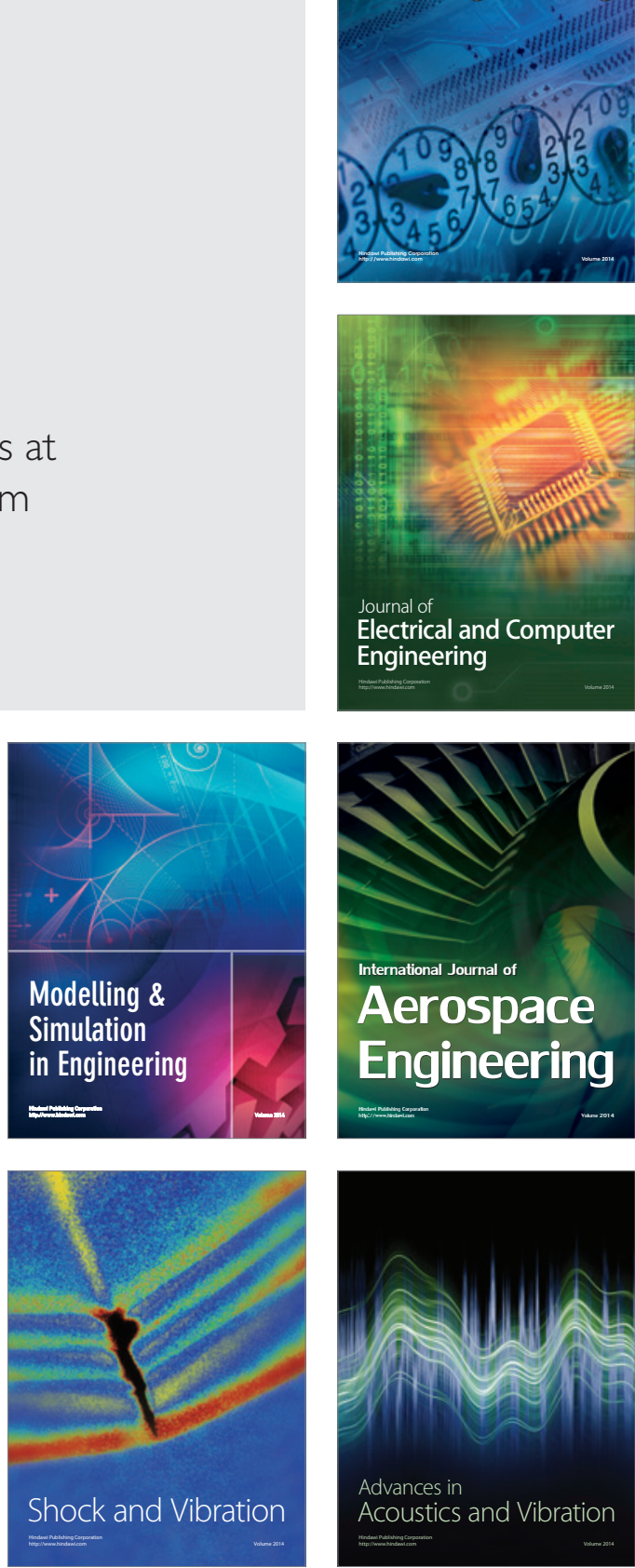